\title{
Classic lobular neoplasia on core biopsy: a clinical and radio-pathologic correlation study with follow-up excision biopsy
}

\author{
Shweta Chaudhary ${ }^{1}$, Loretta Lawrence ${ }^{2}$, Geraldine McGinty ${ }^{3}$, Karen Kostroff ${ }^{4}$ and \\ Tawfiqul Bhuiya ${ }^{1}$ \\ ${ }^{1}$ Department of Pathology, North Shore LIJ Health System, Lake Success, NY, USA; ${ }^{2}$ Breast Imaging, \\ Department of Radiology, North Shore LIJ Health System, Lake Success, NY, USA; ${ }^{3}$ Breast Imaging, \\ Nassau Radiology Medical Associates, Lake Success, NY, USA and ${ }^{4}$ Department of Surgery, \\ North Shore LIJ Health System, Lake Success, NY, USA
}

\begin{abstract}
There are no consensus guidelines for the management of lobular neoplasia diagnosed on core biopsy as the highest risk factor for cancer. This study aimed to assess the risk of upgrade (invasive carcinoma or ductal carcinoma in situ) at the site of the lobular neoplasia and any clinical, radiological or pathologic factors associated with the upgrade. We reviewed all cases with a diagnosis of lobular neoplasia on core biopsy from June 2006 to June 2011. Any cases with radio-pathologic discordance, coexistent lesion that required excision (atypical ductal hyperplasia, flat epithelial atypia, duct papilloma or radial scar) or non-classic variant of lobular carcinoma in situ (pleomorphic, mixed ductal and lobular, lobular carcinoma in situ with necrosis) were excluded from the study. Core biopsy indications included calcification in 35 (40\%), non-mass like enhancement in $19(22 \%)$, mass lesion in $31(36 \%)$ and mass as well as calcification in two cases $(2 \%)$. Follow-up excisions were studied for the presence of upgrade. The study cohort included 87 cases and showed an upgrade of $3.4 \%$ (95\% confidence interval: $1-10 \%)$. Three cases showed an upgrade (one ductal carcinoma in situ and two invasive cancers). All upgraded cases were breast imaging-reporting and data system score $\geq 4$ and associated with atypical duct hyperplasia or in situ or invasive cancer in prior or concurrent biopsies in either breast. The number of cores and lobules involved, pagetoid duct involvement, presence of microcalcification in lobular neoplasia, needle gauge and number of cores obtained showed no correlation with the upgrade. Our results suggest that with radio-pathologic concordance and no prior biopsy proven risk for breast cancer, core biopsy finding of lobular neoplasia as the highest risk lesion can be appropriately and safely managed with clinical and radiologic follow-up as an alternative to surgical excision.

Modern Pathology (2013) 26, 762-771; doi:10.1038/modpathol.2012.221; published online 11 January 2013
\end{abstract}

Keywords: atypical lobular hyperplasia; core biopsy; excision; follow-up; lobular carcinoma in situ; lobular neoplasia; upgrade

Lobular neoplasia that includes atypical lobular hyperplasia and lobular carcinoma in situ was first described by Foote and Stewart in 1941 and later by Haagensen in 1978. ${ }^{1,2}$ Lobular neoplasia are considered risk factors for subsequent invasive carcinoma in either breast with relative risk of 4 to

Correspondence: Dr T Bhuiya, MD, Vice-Chair, Anatomic Pathology, Chief, Division of Surgical Pathology, Department of Pathology and Laboratory Medicine, North Shore - LIJ Health System, 6 Ohio Drive, Ste 202, Lake Success, NY 11042, USA. E-mail: TBhuiya@nshs.edu

Received 6 October 2012; revised 10 November 2012; accepted 14 November 2012; published online 11 January 2013
5 times for atypical lobular hyperplasia and up to 8 to 10 times for lobular carcinoma in situ. ${ }^{3-5}$ The majority of breast cancers that subsequently developed were invasive ductal carcinoma. ${ }^{3-5}$ Classic type lobular carcinoma in situ is defined as a monotonous, discohesive proliferation of small, round cells with low to intermediate nuclear grade, evenly spaced, that both fill and distend $>50 \%$ of the acini of the involved lobular units. ${ }^{6,7}$ Atypical lobular hyperplasia is defined as the same cell population but with $<50 \%$ of the acini filled and distended. ${ }^{6,7}$ Since classic atypical lobular hyperplasia and lobular carcinoma in situ are multicentric and bilateral and considered a marker 
of generalized increase in cancer risk in either breast, ${ }^{4,8}$ surgical excision is unnecessary, just as further surgery is not recommended for patients with lobular neoplasia diagnosed on excision biopsy.

Lobular neoplasia is not associated with any specific clinical abnormality and lacks any diagnostic mammographic features. ${ }^{9}$ Lobular neoplasia may be identified in breast core biopsies as an incidental finding associated with microcalcifications, mass lesion or indeterminate enhancement on imaging. With the advances in breast imaging and increasing use of MRI, the use of core biopsy has greatly increased and is the preferred method for the initial evaluation of most lesions. The diagnosis on core biopsy determines further management. However, there are no consensus guidelines for follow-up management of patients where lobular neoplasia is the highest risk factor lesion. A great variability exists in the management of lobular neoplasia diagnosed on core biopsy. Prior studies have shown upgrade rates ranging from 0 to $35 \%{ }^{5,10-33}$ However, the majority of these studies are limited by one or more of the following factors (a) small number of cases, (b) selection bias when only selected patients underwent excision for this diagnosis, (c) radiologic studies lacking review of pathology slides, (d) inclusion of lobular neoplasia cases with other coexistent high risk lesions such as atypical ductal hyperplasia, (e) inclusion of cases with radio-pathologic discordant core biopsy findings, (f) inclusion of high-risk variants of lobular carcinoma in situ (pleomorphic, mixed lobular and ductal in situ variant and variants with necrosis), (g) inclusion of cases with a second diagnosis such as papilloma, radial scar or flat epithelial atypia warranting an excision. At our institution, excision is routinely performed on all cases with a diagnosis of lobular neoplasia on core biopsy. The aim of our study was to assess the risk of a higher-grade lesion (invasive carcinoma/ductal carcinoma in situ) at the site of the lobular neoplasia diagnosis on core needle biopsy and to assess any clinical, radiological or pathologic factors associated with this upgrade.

\section{Materials and methods}

\section{Case Selection}

After obtaining IRB approval, the surgical pathology data base of the North Shore University Hospital and Long Island Jewish Medical Center was reviewed for all core needle biopsies from June 2006 to June 2011 with a diagnosis of lobular neoplasia, atypical lobular hyperplasia and/or lobular carcinoma in situ. Cases with coexistent invasive carcinoma or ductal carcinoma in situ in the core biopsy specimen were excluded. Cases lacking radiologic studies or biopsy slides were excluded. A total of
113 cases with a diagnosis of lobular neoplasia on core biopsy were identified. Follow-up surgical excision was defined as a surgical procedure (excision biopsy using needle localization or mastectomy) that was performed subsequent to the core biopsy. All but two cases had an excision biopsy or mastectomy performed within 6 days to 4 months after the core biopsy results. One patient status postbilateral malignant lumpectomy had the excision biopsy after 8 months and other patient status post-contralateral breast cancer and chemotherapy had excision biopsy after 24 months. Patients with a diagnosis of invasive carcinoma (ipsilateral or contralateral), ductal carcinoma in situ or pleomorphic lobular carcinoma in situ in prior or concurrent biopsy samples from either breast were intentionally included to determine the disease upgrade in patients with these risk factor for cancer development and had a subset analysis.

\section{Radiologic Review}

The imaging modality that led to a core biopsy (mammogram, ultrasound or MRI) was noted for each case. All core biopsies were performed using ultrasound, stereotactic or MRI guidance. Ultrasound guided biopsies were performed using a 12- or 14-gauge needle. Stereotactic guidance using a vacuum suction probe predominantly used 9-gauge and sometimes 11-gauge needle. MRI guided core biopsies were performed using mostly 9 and sometimes 10 gauge needles. The past history of any breast disease, breast cancer or family history of breast cancer was recorded. Prior breast biopsy findings, if any were recorded. The radiologic findings were categorized as calcifications on mammogram, mass on mammogram, ultrasound or MRI and enhancing lesions on MRI. The breast imaging reporting and data system (BIRADS) ${ }^{34}$ was used to stratify lesions according to different levels of suspicion for carcinoma and was recorded for all cases. The follow-up surgical excision was performed in patients with BIRADS ranging from three to six with the majority of the excised lesions being category 4 and above. The radiologic findings were correlated with core needle biopsy diagnosis for each case. One case was excluded because of radio-pathologic discordance, an 8-mm stellate enhancing lesion on MRI diagnosed as lobular carcinoma in situ and proliferative fibrocystic disease on core biopsy while excision biopsy showed ductal carcinoma in situ and $2 \mathrm{~mm}$ infiltrating tubular and lobular carcinoma with adjacent fat necrosis.

\section{Pathology Review}

Core biopsy specimens varied from 3-16 cores under MRI guidance, 2-15 cores under stereotactic guidance and 2-10 cores under ultrasound 
guidance. Core biopsy tissue specimens were fixed in $10 \%$ formalin, embedded in paraffin and stained with hematoxylin and eosin. Up to three cores were submitted in one cassette. The tissue was sectioned at $4-\mu \mathrm{m}$ intervals. For most of the cases, two slides with sections at two different levels from all blocks (varying from 1 to 6) were studied with the exception of nine cases where only one level was studied and two cases where up to 16 levels were studied to ascertain the presence of calcification. The core biopsy for all cases was reviewed using Page's criteria. ${ }^{6}$ Lobular carcinoma in situ was further classified as classic type, pleomorphic, or lobular carcinoma in situ with necrosis. Since E-cadherin has a role in categorization of ambiguous in situ carcinomas, ${ }^{35}$ it was performed in cases with an equivocal ductal/lobular morphology or in cases of pleomorphic lobular carcinoma in situ. In the study cohort, E-cadherin was performed on 14/87 $(16 \%)$ cases with negative results confirming lobular origin of the lesion. All core biopsy slides were reviewed for the number of cores and lobules involved by lobular neoplasia, pagetoid duct involvement, lobular carcinoma in situ variant (type A/B), presence of necrosis, presence and distribution of microcalcification and coexistent benign findings accounting for radiologic concordance. Five cases were excluded following review of core biopsy slides as they did not fulfilled criteria for a diagnosis of lobular neoplasia. Five cases with pleomorphic lobular carcinoma in situ component were excluded. Fifteen cases with concurrent findings considered as risk factors that would necessitate an excision biopsy (one case with atypical ductal hyperplasia, seven cases with flat epithelial atypia, four cases of intraductal papilloma, two cases of radial scar, and one case with intraductal papilloma and radial scar) were excluded from the study. In all, 87 cases qualified for inclusion in the study. Follow-up resection specimens included 76 excision biopsy using needle localization, 1 partial mastectomy and 10 modified radical mastectomies). Appropriate follow-up excision biopsy was confirmed by radiologic correlation of clip removal and documentation of biopsy site changes on excision specimens. In all, $48 / 76(63 \%)$ of the excision biopsy specimens were submitted entirely for microscopic examination. In all, 28/76 (37\%) cases were partially submitted with submission of the entire area of interest with adjacent tissue, extensive sampling of any fibrous tissue beyond this area and representative sampling of remaining fatty breast tissue. Mostly this protocol lead to extensive sampling and accounted for $>90 \%$ specimen submission for microscopy. Follow-up excision specimen were reviewed for the presence of biopsy site changes, number of slides involved by residual lobular neoplasia and presence of any upgrade lesions (ductal carcinoma in situ, invasive lobular carcinoma, invasive ductal carcinoma).

\section{Data Analysis}

The presence of an invasive carcinoma and/or ductal carcinoma in situ located in the region of the initial biopsy site containing lobular neoplasia defined the lesion upgrade. The number of cases with diagnosis of lobular neoplasia on core biopsy specimens that upgraded on excision biopsy was determined. 95\% confidence interval (CI) was calculated. Data were analyzed for any clinical, radiologic and histopathologic factors predicting the upstage of isolated lobular neoplasia on the core biopsy. Patients with prior history of carcinoma and prior biopsy proven risk factor for cancer were analyzed as a subset. The upgrade rates in the excluded cases were assessed and compared with the study cohort.

\section{Results}

Our study population consisted of 83 females and 87 core biopsies with four of our patients having two biopsies each. The age ranged from 37 to 88 years with a mean age of 55 years. Fifty cases were from the left breast and 37 cases were from the right breast. The core biopsy indication included calcification in 35 (40\%), non-mass like enhancement in $19(22 \%)$, mass lesion in $31(36 \%)$ and mass as well as calcification in 2 cases (2\%). Core biopsy was performed using US guidance in 19 (21.8\%), MRI guidance in $32(36.7 \%)$ and stereotactic guidance in $36(41.4 \%)$ cases. The needle gauge varied from 9 to 14 with 9 gauge used for 57 cases (66\%), 10 gauge for 2 cases (2\%), 11 gauge for 9 cases (10\%), 12 gauge for 9 cases $(10 \%), 14$ gauge for 10 cases $(12 \%)$. Of our study cohort, 13 patients had a family history of breast cancer, 28 a history of breast cancer (2 bilateral, 16 contralateral and 10 ipsilateral), 5 a history of benign breast disease, 4 a history of prior LCIS and 1 a history of prior multifocal atypical duct hyperplasia associated with lobular carcinoma in situ in the ipsilateral breast. The number of cores varied from 2-16 cores but averaged approximately 9 for MRI, 8 for stereotactic and 4.5 for ultrasound guided biopsies.

The imaging indications for core biopsy and benign lesions associated with lobular neoplasia found on core biopsy are enumerated (Table 1). The majority of cases were 'type A' lobular carcinoma in situ except two cases of 'type B' variant, both of which were negative for E-cadherin on immunostaining. None of the 87 case of lobular neoplasia was associated with necrosis/ comedonecrosis on core biopsy.

In all, 11 cases showed pagetoid duct involvement by classic lobular neoplasia but none of the upgraded lesion showed pagetoid duct involvement. In all, 8/11 cases with pagetoid duct involvement had $>4$ lobules and more than half of all cores involved. In three cases, pagetoid involvement was 
associated with $<2$ lobules involved by lobular neoplasia in a single core. Pagetoid duct involvement by lobular neoplasia showed neither specific association with extent of involvement by lobular carcinoma in situ nor any correlation with lesion upgrade.

In all, 11/36 (30\%) of core biopsies performed for mammographic calcification showed focal microcalcification within the lobular neoplasia. Of all lobular neoplasia cases, 19/ 87 cases $(21.8 \%)$ showed focal microcalcification within the lobular neoplasia component (17 type 'A' and two Type 'B' lobular carcinoma in situ). Eleven of these 19 cases (58\%) were performed for mammographic calcification. Additionally, all of these cases had prominent

Table 1 Lesions associated with lobular neoplasia on core needle biopsies

Number of cases

Lesion with mammographic calcifications
Columnar cell change and hyperplasia
Proliferative fibrocystsic change
Benign breast and ducts
Non-proliferative fibrocystic change
Sclerosing adenosis
Fibroadenoma
Mass lesion associated with lobular neoplasia
Fibroadenoma
Proliferative Fibrocystic change
Sclerosing adenosis
Nodular stromal fibrosis
Fat necrosis
Nodular LCIS
Enhancing lesion on MRI
Nodular adenosis
Non-proliferative fibrocystic change
Proliferative fibrocystsic change
Columnar cell hyperplasia
Fibroadenomatoid nodule with lobular
carcinoma in situ
Pseudoangiomatous stromal hyperplasia
Lesion presenting as mass and calcification
Fibrocystic change
Sclerosing adenosis

7

6

2

12

7

1

1

7

6

3

1

1

1
aMagnetic resonance imaging.

microcalcifications in other benign breast components such as columnar cell change, columnar cell hyperplasia, proliferative fibrocystic change and sclerosing adenosis. Both cases of type B lobular carcinoma in situ were biopsied for microcalcification detected on mammogram and both had columnar cell hyperplasia with microcalcifications. The remaining eight cases had no calcification detectable on radiology, suggesting that the calcification associated with lobular carcinoma in situ is usually incidental and may not be detectable radiographically. Only two cases with microcalcifications in lobular neoplasia had lesion upgrade in follow-up biopsy whereas 17 cases with microcalcification showed no lesion upgrade on follow-up surgical excision.

The number of cores and terminal duct lobular units involved by lobular neoplasia on core biopsy showed no correlation with lesion upgrade but was associated with the volume of lobular neoplasia on follow-up surgical excision (Table 2).

In all, 87 core biopsies with lobular neoplasia as the highest risk lesion were comprised of 22 atypical lobular hyperplasia, 44 lobular carcinoma in situ and 21 with both atypical lobular hyperplasia and lobular carcinoma in situ. Follow-up excision biopsies showed an upgrade rate of $3.4 \%$ (95\% CI: $0-10 \%$ ). All the upgrades were seen in association with lobular carcinoma in situ (Figure 1; Table 3). For atypical lobular hyperplasia alone as the highest risk factor, none of the case showed upgrade. The needle gauge used or the number of cores obtained showed no correlation with the lesion upgrade. Two of the upgraded cases with invasive cancer on the excision had BIRADS of 6 and a history of bilateral cancer and contralateral DCIS, respectively. The third case had a history of multifocal ADH that showed an upgrade to DCIS and also showed focal pleomorphic lobular carcinoma in situ on excision (Table 4). Excluding the patients with synchronous and prior breast cancer/ductal carcinoma in situ, only a single case showed an upgrade 1.7\% (1/59).

Also, two of our lobular neoplasia cases showed extensive pleomorphic lobular carcinoma in situ and single focus of atypical ductal hyperplasia on excision. Both of these lesion were in elderly

Table 2 Upgrade and extent of lobular involvement in various categories

\begin{tabular}{lccc}
\hline & $>4$ Lobules & $>1$ Lobule/core & Upgrade \\
\hline Benign beast disease & $3 / 5$ & $0 / 5$ & None \\
Bilateral breast cancer & $2 / 2$ & $1 / 2$ & 1 Upgrade \\
Ipsilateral breast cancer & $7 / 9$ & $1 / 9$ & None \\
Ipsilateral ductal carcinoma in situ & $1 / 1$ & $0 / 1$ & None \\
Contralateral breast cancer & $2 / 14$ & $0 / 14$ & None \\
Contralateral ductal carcinoma in situ & $0 / 2$ & $0 / 2$ & 1 Upgrade \\
Routine screening & $11 / 36$ & $1 / 36$ & None \\
Prior lobular carcinoma in situ & $2 / 4$ & $0 / 4$ & None \\
Multifocal atypical duct hyperplasia & $1 / 1$ & $0 / 1$ & 1 Upgrade \\
Family history of breast cancer & $4 / 13$ & $1 / 13$ & None \\
\hline
\end{tabular}




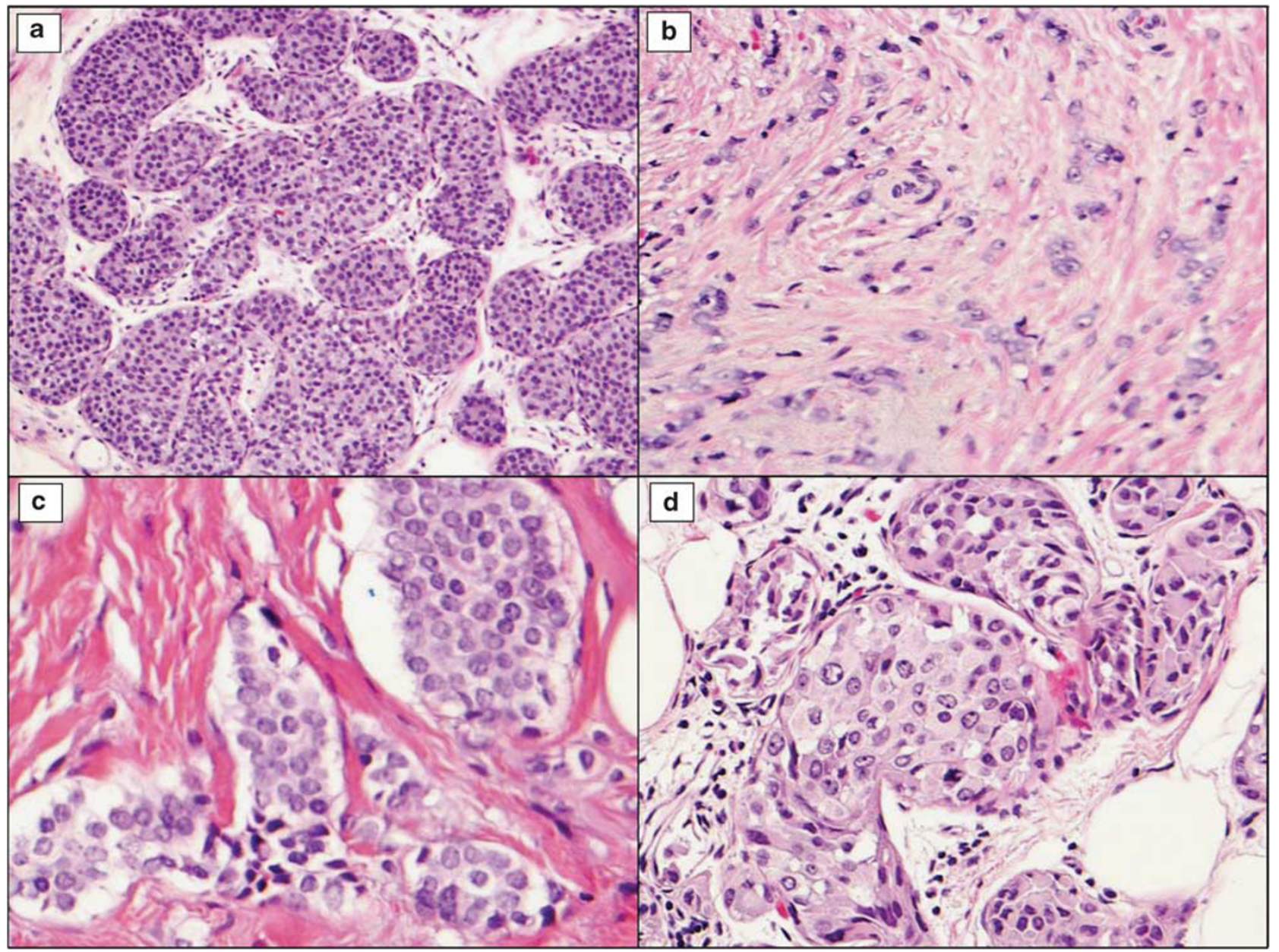

Figure 1 Lobular carcinoma in situ on core needle biopsy and the excision of upgraded cases. (a) Classic lobular carcinoma in situ on core biopsy $(\mathrm{H} \& \mathrm{E} \times 100)$. (b) Upgrade to invasive lobular cancer on excision $(\times 200)$. (c) Upgrade to invasive cancer on excision $(\times 200)$. (d) Upgrade to ductal carcinoma in situ on excision $(\times 200)$.

Table 3 Comparison of upgrade rates on study cohort and excluded cases

\begin{tabular}{lcc}
\hline & $\begin{array}{c}\text { Study } \\
\text { cohort }\end{array}$ & $\begin{array}{c}\text { Excluded } \\
\text { case cohort }\end{array}$ \\
\hline $\begin{array}{l}\text { Lobular neoplasia on core biopsy } \\
\begin{array}{l}\text { Atypical lobular hyperplasia on } \\
\text { core biopsy }\end{array}\end{array}$ & $\begin{array}{l}3.4 \%(3 / 87) \\
\text { None }(0 / 22)\end{array}$ & $\begin{array}{c}19.0 \%(4 / 21) \\
25 \%(1 / 4)\end{array}$ \\
$\begin{array}{l}\text { cobular carcinoma in situ on } \\
\text { core biopy }\end{array}$ & $4.6 \%(3 / 65)$ & $17.6 \%(3 / 17)$ \\
\hline
\end{tabular}

patients ( $>80$ years) and performed for mammographic calcifications.

Subset analysis performed in patients with various risk factors showed an upgrade rate of $7.1 \%$ $(2 / 28)$ for patients with synchronous ipsilateral or contralateral breast cancer or ductal carcinoma in situ and $0 \%$ for patients undergoing screening mammogram (0/13) or prior history of benign breast disease $(0 / 5)$ or prior lobular carcinoma in situ as the highest risk lesion (0/4). One upgrade was seen in a patient with a prior biopsy diagnosis of multifocal atypical duct hyperplasia in the ipsilateral breast (Table 5).

The cohort of excluded cases showed an upgrade rate of $19 \%$ for lobular neoplasia. The upgrade was seen in one case with radio-pathologic discordance, two cases with pleomorphic lobular carcinoma in situ and one case with flat epithelial atypia and mucocele like lesion (Table 6). All upgraded cases in the excluded case cohort showed the upgraded lesion to be at a distant site from the site of classic lobular carcinoma in situ and near the coexistent risk lesion in all cases, suggesting that lobular carcinoma in situ is purely an incidental finding in these cases.

\section{Discussion}

Lobular neoplasia are often multifocal and not uncommonly present in the contralateral breast. ${ }^{5,8,36-39}$ Up to $50 \%$ of patients with lobular carcinoma in situ have multifocal disease in the ipsilateral breast and up to one third in the contralateral breast. ${ }^{39,40}$ 
Table 4 Clinical and histologic features of the cases in study cohort with upgrade on excision

\begin{tabular}{|c|c|c|c|c|c|c|c|c|}
\hline & Age & Clinical history & Radiology (MRI) & $\begin{array}{l}\text { Needle } \\
\text { gauge }\end{array}$ & $\begin{array}{l}\text { Core biopsy } \\
\text { findings }\end{array}$ & $B I R A D S$ & $\begin{array}{l}\text { No. of cores } \\
\text { involved }\end{array}$ & Upgrade lesion \\
\hline 1 & 47 & Bilateral IDC & $\begin{array}{l}5 \mathrm{~mm} \text { nodular } \\
\text { indeterminate } \\
\text { enhancement } \\
7 \mathrm{~mm} \text { from } \\
\text { tumor satellite } \\
\text { nodule }\end{array}$ & 10 & CCC, PFCC & 6 & $5 / 8$ & $\begin{array}{l}\text { Invasive mammary } \\
\text { carcinoma (ductal and } \\
\text { lobular features), } 6 \mathrm{~mm}\end{array}$ \\
\hline 2 & 68 & Contra lateral DCIS & $\begin{array}{l}\text { Lobulated } \\
\text { enhancing mass } \\
(6 \mathrm{~mm})\end{array}$ & 9 & $\begin{array}{l}\text { PFCC with } \\
\text { microcalcifications, } \\
\text { Apocrine metaplasia }\end{array}$ & 6 & $1 / 8$ & $\begin{array}{l}\text { Invasive lobular } \\
\text { carcinoma ( } 4 \mathrm{~mm} \text { ) }\end{array}$ \\
\hline 3 & 57 & $\begin{array}{l}\text { Multifocal ADH, } \\
\text { LCIS }\end{array}$ & $\begin{array}{l}5 \mathrm{~mm} \text { rim } \\
\text { enhancing } \\
\text { nodule }\end{array}$ & 9 & CCC, PFCC & $4 a$ & $4 / 7$ & DCIS, P-LCIS \\
\hline
\end{tabular}

ADH, atypical ductal hyperplasia; CCC, columnar cell change; DCIS, ductal carcinoma in situ; IDC, invasive ductal carcinoma; LCIS, lobular carcinoma in situ; PFCC, proliferative fibrocystic change; P-LCIS, pleomorphic lobular carcinoma in situ.

Table 5 Upgrades in different clinical groups in study cohort

\begin{tabular}{lc}
\hline Clinical group & $\begin{array}{c}\text { Number of } \\
\text { upgrades }\end{array}$ \\
\hline $\begin{array}{l}\text { Ipsilateral or contralateral breast cancer or } \\
\text { ductal carcinoma in situ }\end{array}$ & $2 / 28$ \\
$\begin{array}{l}\text { Prior biopsy with atypical duct hyperplasia } \\
\text { Screening for family history of breast cancer }\end{array}$ & $1 / 1$ \\
Prior biopsy with lobular carcinoma in situ & $0 / 13$ \\
as the highest risk factor & $0 / 4$ \\
$\begin{array}{l}\text { Benign breast disease } \\
\text { Routine mammographic screening, no risk } \\
\text { factor or prior history }\end{array}$ & $0 / 5$ \\
& \\
\hline
\end{tabular}

Table 6 Etiology of upgrades in the excluded case cohort

\begin{tabular}{lc}
\hline Exclusion criteria & $\begin{array}{c}\text { Number of } \\
\text { upgrade }\end{array}$ \\
\hline Radio-pathologic discordance & $1 / 1$ \\
Pleomorphic lobular carcinoma in situ & $2 / 5$ \\
Other coexistent lesions which may warrant & $1 / 15$ \\
excision (ADH, FEA, IDP, RS) &
\end{tabular}

ADH, atypical ductal hyperplasia; FEA, flat epithelial atypia; IDP, intraductal papilloma; RS, radial scar.

Determining the incidence of lobular neoplasia is difficult as there is no radiologic correlate. ${ }^{25}$ The incidence of lobular neoplasia has increased fourfold over the last 20 years, a consequence of the increase in the frequency of core biopsies and the greater amount of tissue acquired through the larger bore vacuum suction needles. ${ }^{41}$

Lobular neoplasia is rare as an isolated lesion and is usually found coexisting with other lesions that may pose some risk for cancer development and would therefore be subject to a follow-up excision biopsy. The inclusion of such cases is a cause of bias in multiple previous studies and makes the explicit studies for upgrade difficult. Numerous studies have evaluated the need for excision following a diagnosis of lobular neoplasia on core biopsy (Table 7). Our study had no selection bias as all patients at our hospital diagnosed with lobular neoplasia on core biopsy undergo routine excision. The case selection criteria were stringent including only unambiguous cases of classic variant of lobular carcinoma in situ as the highest risk factor lesion without coexisting lesions associated with risk for cancer development.

Only $30 \%$ of cases performed for microcalcification on imaging showed focal calcification in the lobular carcinoma in situ component with the predominant calcifications seen in columnar cell change and hyperplasia, sclerosing adenosis, proliferative and non-proliferative fibrocystic change, fibroadenoma and unremarkable breast tissue. Zhao et $a l^{33}$ also focused on lobular neoplasia presenting with microcalcification on imaging and reported the presence of calcium mainly in fibrocystic changes, columnar cell changes and unremarkable breast tissue and stroma.

Radiopathologic concordance is essential in the follow-up evaluation as discordant correlation may lead to a false positive lesion upgrade demonstrated in recent studies by Hwang et al, ${ }^{17}$ Menon et $a l,{ }^{23}$ and Nagi et al. ${ }^{25}$ Discordant radio-pathologic correlation includes the presence of a mass lesion, indeterminate enhancement or suspicious calcifications on imaging that cannot be explained by the presence of lobular neoplasia or other coexisting lesion on the needle biopsy. Rarely, lobular carcinoma in situ can produce a nodular mass and present as a nodular lesion or enhancement on MRI. One of the cases in our study presented as an 8-mm nodular enhancement on MRI and core biopsy revealed nodular lobular carcinoma in situ measuring $6 \mathrm{~mm}$. Zhang et $a l^{42}$ recently reported a case of lobular carcinoma in situ presenting as a 20-mm solid mass. 
Table 7 Literature review

\begin{tabular}{|c|c|c|c|c|c|c|c|}
\hline Study & $\begin{array}{l}\text { LN with } \\
\text { follow-up } \\
\text { excision }\end{array}$ & $\begin{array}{l}\text { Excision } \\
\text { rate }\end{array}$ & $\begin{array}{c}\# \\
\text { Upgrade } \\
(\%)\end{array}$ & $\begin{array}{c}P \text {-LCIS } \\
\text { excluded }\end{array}$ & $\begin{array}{l}\text { Slides } \\
\text { reviewed }\end{array}$ & $\begin{array}{l}\text { Radiologic } \\
\text { discordance } \\
\text { excluded }\end{array}$ & Comments \\
\hline Arpino et $a l^{10}$ & 21 & $47 \%$ & $3(14 \%)$ & NM & Yes & NM & $\begin{array}{l}\text { One upgrade was a mass lesion and other two were } \\
\text { calcification associated }\end{array}$ \\
\hline Berg et $a l^{11}$ & 15 & $60 \%$ & $1(7 \%)$ & No & NM & NA & $\begin{array}{l}\text { All cases excised because of coexistent diagnosis of ADH, } \\
\text { DCIS or invasive cancer }\end{array}$ \\
\hline Brem et $a l^{12}$ & 164 & $59 \%$ & $38(23 \%)$ & NM & No & $\mathrm{NA}^{\mathrm{a}}$ & $\begin{array}{l}21 \text { Upgrades mass lesion, higher BIRADS, core biopsy, fewer } \\
\text { specimen }\end{array}$ \\
\hline $\begin{array}{l}\text { Cangiarella } \\
\text { et a } 1^{13}\end{array}$ & 38 & $\mathrm{NA}^{\mathrm{b}}$ & $3(8 \%)$ & NM & NM & No & 2 Upgrades had discordant radiology \\
\hline Crisi et $a 1^{14}$ & 16 & $46 \%$ & $2(13 \%)$ & No & Yes & No & Both upgrades had mass on imaging \\
\hline $\begin{array}{l}\text { Elsheikh and } \\
\text { Silverman }^{5}\end{array}$ & 33 & NA & $9(27 \%)$ & No & Yes & No & $\begin{array}{l}\text { Upgrade with } P \text {-LCIS, synchronous C/L DCIS, mass on } \\
\text { imaging missed by core biopsy }\end{array}$ \\
\hline $\begin{array}{l}\text { Esserman } \\
\text { et al }{ }^{15}\end{array}$ & 35 & $74 \%$ & $3(9 \%)$ & NM & Yes & No & $\begin{array}{l}\text { Diffuse LCIS ( }>1 \text { lobule/core) and one case with residual } \\
\text { calcification }\end{array}$ \\
\hline Foster et al ${ }^{16}$ & 26 & $74 \%$ & $6(23 \%)$ & NM & No & NM & 2 Upgrades were mass on imaging \\
\hline Hwang et $a l^{17}$ & 87 & $31 \%$ & $10(11 \%)$ & No & Yes & No & $\begin{array}{l}6 \text { Discordant imaging, } 2 P \text { - LCIS or } 1 \text { LCIS with necrosis, } \\
1 \text { slide not reviewed }\end{array}$ \\
\hline $\begin{array}{l}\text { Karabakhtsian } \\
\text { et } \text { l }^{18}\end{array}$ & 92 & $91 \%$ & $10(11 \%)$ & Yes & Yes & No & $\begin{array}{l}2 \text { Upgrades were mass lesion and } 4 \text { cases with neoplastic } \\
\text { epithelium associated microcalcification }\end{array}$ \\
\hline Lewis et al ${ }^{19}$ & 201 & $71 \%$ & $26(13 \%)$ & No & No & NM & $\begin{array}{l}\text { No mention of the radio-pathologic concordance of upgrade } \\
\text { cases }\end{array}$ \\
\hline $\begin{array}{l}\text { Liberman } \\
\text { et } a l^{20}\end{array}$ & 9 & $81 \%$ & $2(22 \%)$ & No & Yes & No & Mixed ductal LCIS upgraded, no classic pure LN upgraded \\
\hline $\begin{array}{l}\text { Mahoney } \\
\text { et } a l^{21}\end{array}$ & 20 & $74 \%$ & $5(25 \%)$ & No & Yes & No & $\begin{array}{l}1 \text { Upgrade for mass lesion, } 1 P \text {-LCIS and } 1 \text { had concurrent } \\
\text { C/L breast cancer }\end{array}$ \\
\hline $\begin{array}{l}\text { Margenthaler } \\
\text { et al }\end{array}$ & 35 & $85 \%$ & $7(20 \%)$ & NM & NM & No & $\begin{array}{l}\text { Presence of mammographic mass was associated with } \\
\text { increased upgrade rate }\end{array}$ \\
\hline Menon et $a l^{23}$ & 25 & $53 \%$ & $8(32 \%)$ & No & $\mathrm{Yes}^{\mathrm{e}}$ & No & $\begin{array}{l}7 \text { Discordant imaging (biopsy missed mass in } 5 \text { and } \\
\text { calcification in } 2 \text { cases }\end{array}$ \\
\hline $\begin{array}{l}\text { Middleton } \\
\text { et } a l^{24}\end{array}$ & 17 & $49 \%$ & $6(35 \%)$ & Yes & Yes & No & $\begin{array}{l}\text { 6/6 Upgrades were for mass on imaging which were missed } \\
\text { on core biopsy }\end{array}$ \\
\hline Nagi et $a l^{25}$ & 45 & $46 \%$ & $2(4.4 \%)$ & Yes & Yes & Yes & $\begin{array}{l}\text { One NB classified as DCIS on review and second case had } \\
\text { minute focus of ILC away from the lesion (incidental finding) }\end{array}$ \\
\hline O’ Neil et $a 2^{26}$ & 27 & $60 \%$ & $5(19 \%)$ & NM & Yes & No & - \\
\hline Rendi et $a l^{27}$ & 68 & $89 \%$ & $3(4.4 \%)$ & Yes & Yes & No & $\begin{array}{l}\text { Discordant imaging, extensive LCIS ( }>4 \text { TDLUs involved), } \\
\text { high-risk patients }\end{array}$ \\
\hline $\begin{array}{l}\text { Renshaw } \\
\text { et } a l^{28}\end{array}$ & 15 & $21 \%$ & $3(3 \%)$ & No & NM & No & $\begin{array}{l}1 \text { Upgrade non-classic LCIS, } 2 \text { carcinomas were away from } \\
\text { biopsy site }\end{array}$ \\
\hline $\begin{array}{l}\text { Shah- Khan } \\
\text { et } a l^{29}\end{array}$ & 101 & $55 \%$ & $2(2 \%)$ & Yes & Yes & $\mathrm{No}^{\mathrm{d}}$ & One upgrade radio-pathologically discordant \\
\hline $\begin{array}{l}\text { Shin and } \\
\text { Rosen }^{30}\end{array}$ & 13 & $\mathrm{NA}^{\mathrm{C}}$ & $2(15 \%)$ & Yes & Yes & No & Radiologic concordance not discussed \\
\hline $\begin{array}{l}\text { Subhawong } \\
\text { et } a l^{31}\end{array}$ & 56 & $48 \%$ & $0(0 \%)$ & NA & Yes & Yes & Focused on minimal ALH ( $\leq 3$ foci) only \\
\hline Yeh et $a l^{32}$ & 15 & NA & $1(7 \%)$ & NM & Yes & No & Radiologi \\
\hline Zhao et $a l^{33}$ & 237 & $70 \%$ & $11(4.6 \%)$ & Yes & $\begin{array}{l}\text { Yes (the } \\
\text { upgraded cases) }\end{array}$ & Yes & Study focused only on LN associated with calcification \\
\hline Present study & 87 & $100 \%$ & $3(3.4 \%)$ & Yes & Yes & Yes & $\begin{array}{l}\text { Upgrades in synchronous cancer, C/L DCIS and prior biopsy } \\
\text { proven multifocal ADH in ipsilateral breast }\end{array}$ \\
\hline
\end{tabular}

ADH, atypical ductal hyperplasia; ALH, atypical lobular hyperplasia; BIRADS, breast imaging reporting and data system; DCIS, ductal carcinoma in situ; LCIS, lobular carcinoma in situ; LN, lobular neoplasia; NA, not applicable; NM, not mentioned; P-LCIS, pleomrophic lobular carcinoma in situ; TDLU, terminal duct lobular unit.

${ }^{a}$ No standardization between participating institutions.

${ }^{\mathrm{b}}$ The cases without surgical excision follow-up were excluded.

${ }^{\mathrm{c}}$ Included 20 non-consecutive biopsies with follow-up excision.

$\mathrm{d}_{93 \%} \%$ Radiologic pathologic concordance.

${ }^{\mathrm{e}} \mathrm{Six}$ core biopsies were not available, hence not reviewed.

Studies by Hwang et $a,^{17}$ Fadare et $a l,{ }^{43}$ and Liberman et $a l^{20}$ suggested that pleomorphic and classic lobular carcinoma in situ associated with necrosis show a high upgrade rate and recommended excision for all such cases. Many of the studies performed on lobular neoplasia have higher upgrades because of inclusion of pleomorphic lobular carcinoma in situ or mixed ductal lobular carcinoma in situ or lobular carcinoma in situ with comedonecrosis.
Other studies are compromised because of inclusion of risk factors for cancer such as atypical duct hyperplasia, radial scar lesions, duct papilloma for which an excision biopsy is usually performed. Karabakhtsian et $a l^{18}$ excluded cases with atypical duct hyperplasia, intraductal papilloma and radial scar. Rendi et $a^{27}$ excluded cases of atypical duct hyperplasia but not mention excluding other lesions such as duct papilloma, radial scar and flat epithelial atypia. 
Details of prior history and biopsies are also required to exclude cases with a prior history of synchronous ipsilateral/contralateral breast cancer or ductal carcinoma in situ. Cangiarella et al ${ }^{13}$ did not mention if their upgraded cases had such a past history.

Excluding patients with synchronous and prior invasive breast cancer and ductal carcinoma in situ, the upgrade rate in our study was $1.7 \%(1 / 59)$ similar to study by Hwang et $a l^{17}$ of $1 \%$ after exclusion of cases with discordant radio-pathologic findings and non-classic lobular carcinoma in situ morphology. They concluded that classic lobular carcinoma in situ with concordant radiology and pathology can be appropriately managed by clinical follow-up without surgery. In all, 32\% (28/87) of our study cohort had a history of either previous or synchronous ipsilateral, contralateral or bilateral invasive cancer/DCIS similar to the findings in the study by Hwang et al. ${ }^{17}$

In the present study where excision was routinely performed for all lobular neoplasia diagnosed on core biopsy, the upgrade rate was $3.4 \%$. However, all the upgraded cases had a biopsy proven history of a risk factor (multifocal atypical duct hyperplasia, invasive ductal cancer, and ductal carcinoma in situ). Therefore, we suggest that classic lobular neoplasia as the highest risk lesion with radiopathologic concordance and no other biopsy proven risk factors for breast cancer development can be appropriately and safely managed with clinical and radiologic follow-up. This study provides an accurate assessment and unbiased upgrade rates with a good sample size and constitutes a useful reference for patient management.

Rendi et $a l^{27}$ in their study found that extensive lobular carcinoma in situ $>4$ terminal duct lobular unit's involvement accounted for lesion upgrade and recommend excision. Esserman et $a l^{15}$ suggested that diffuse lobular neoplasia (involvement of $>1$ lobule per core) may indicate an associated invasive cancer and should prompt excision. We did not find any correlation between the extent of lobular neoplasia or pagetoid involvement and lesion upgrade. Middleton et al in their study concluded that lobular carcinoma in situ involving adenosis and with pagetoid spread on core biopsy did not show a more significant lesion on excision. ${ }^{23}$

In all, $21.8 \%$ of our lobular neoplasia cases showed lobular carcinoma in situ associated calcification but the presence of calcification does not correlate with lesion upgrade. Middleton et al also reported that lobular carcinoma in situ associated calcification does not portend any higher-grade lesion in the excision biopsy. ${ }^{23}$

In one of the cases with synchronous prior biopsy proven ductal carcinoma in situ in the ipsilateral breast, the core biopsy showed lobular carcinoma in situ along with proliferative fibrocystic change and $5 \mathrm{~mm}$ nodular stromal fibrosis for a $6-\mathrm{mm}$ indeterminate enhancement and BIRADs of $4 \mathrm{~b}$ on
MRI. Mastectomy performed later showed multifocal extensive ductal carcinoma in situ and no lobular carcinoma in situ. Clearly ductal carcinoma in situ does not represent an upgrade as it is not directly related to the site of lobular carcinoma in situ and had no association with the lobular carcinoma in situ in the resection specimen. The prior biopsy proven ductal carcinoma in situ in same breast was a major risk factor for development of cancer and the presence of lobular carcinoma in situ was an incidental finding.

Another of our cases showed extensive pleomorphic lobular carcinoma in situ on excision. Core biopsy performed for calcification with a BIRADS of 4a showed predominant calcification in benign breast tissue and focal classic lobular carcinoma in situ with microcalcifications. The excision biopsy showed extensive pleomorphic lobular carcinoma in situ with comedonecrosis. This case emphasizes the fact that calcification with a BIRADS of 4 cannot be explained by classic lobular neoplasia and benign breast tissue calcification and should be treated with excision.

A third case of needle biopsy performed for indeterminate calcification on mammogram and BIRADS of 4 showed fibroadenomatoid change with nodular fibrosis and calcification in proliferative fibrocystic disease and focal atypical lobular hyperplasia. The follow-up resection showed lobular carcinoma in situ (8/15 slides), atypical lobular hyperplasia, flat epithelial atypia and single adjacent focus of atypical duct hyperplasia, suggesting that the presence of flat epithelial atypia and atypical duct hyperplasia are confounding risk factors. ${ }^{44}$

In conclusion, with a good sample size, appropriate radiologic pathologic correlation, optimal sampling and exclusion of other coexistent risk factors lesions in core biopsy, our study showed a $3.4 \%(95 \%$ CI, $1-10 \%)$ upgrade on follow-up excision for classic lobular neoplasia on core biopsy. However, all three upgrades had biopsy proven risk factor for cancer development. A BIRADS score of 4 or above may be associated with a lesion upgrade. The number of cores and lobules involved, pagetoid duct involvement, presence of microcalcification in lobular neoplasia, classic lobular carcinoma in situ (type A or B), needle gauge and number of cores are not associated with an upgrade on excision. This study highlights the benign outcome for classic lobular neoplasia as the highest risk factor lesion on core biopsy and suggests that non-surgical management with clinical and radiologic follow-up is an appropriate and safe alternative to surgical excision in these patients.

\section{Acknowledgements}

We acknowledge Dr Leonard B Kahn for proof reading the manuscript. 


\section{Disclosure/conflict of interest}

The authors declare no conflict of interest.

\section{References}

1 Foote FW Jr, Stewart FW. Lobular carcinoma in situ. A rare form of mammary cancer. Am J Pathol 1941;17:491-496.

2 Haagensen CD, Lane $\mathrm{N}$, Lattes $\mathrm{R}$, et al. Lobular neoplasia (so-called lobular carcinoma in situ) of the breast. Cancer 1978;42:737-769.

3 Page DL, Dupont WD, Rogers LW, et al. Atypical hyperplastic lesions of the female breast. A long-term follow- up study. Cancer 1985;55:2698-2708.

4 Page DL, Kidd TE Jr, Dupont WD, et al. Lobular neoplasia of the breast: higher risk for subsequent invasive cancer predicted by more extensive disease. Hum Pathol 1991;22:1232-1239.

5 Elsheikh TM, Silverman JF. Follow-up surgical excision is indicated when breast core needle biopsies show atypical lobular hyperplasia or lobular carcinoma in situ: a correlative study of 33 patients with review of the literature. Am J Surg Pathol 2005;29: 534-543.

6 Page DL, Anderson TJ, Rogers LN. Lobular carcinoma in situ, In: Page DL, Anderson TJ(eds). Diagnostic Histopathology of the Breast. New York. Churchill: Livingston, 1987;174-182.

7 Rosen PP (editor). Rosen's Breast Pathology, 2nd ed. Lippincott Williams \& Wilkins: Philadelphia; 2001, pp 209-222.

8 Rosen PP, Kosloff C, Lieberman PH, et al. Lobular carcinoma in situ of the breast. Detailed analysis of 99 patients with average follow-up of 24 years. Am J Surg Pathol 1978;2:225-251.

9 Beute BJ, Kalisher L, Hutter RVP. Lobular carcinoma in situ of the breast: clinical, pathologic, and mammographic features. AJR Am J Roentgenol 1991;157: 257-265.

10 Arpino G, Allred DC, Mohsin SK, et al. Lobular neoplasia on core-needle biopsy-clinical significance. Cancer 2004;101:242-250.

11 Berg WA, Mrose HE, Ioffe OB. Atypical lobular hyperplasia or lobular carcinoma in situ at core-needle breast biopsy. Radiology 2001;218:503-509.

12 Brem RF, Lechner MC, Jackman RJ, et al. Lobular neoplasia at percutaneous breast biopsy: variables associated with carcinoma at surgical excision. AJR Am J Roentgenol 2008;190:637-641.

13 Cangiarella J, Guth A, Axelrod D, et al. Is surgical excision necessary for the management of atypical lobular hyperplasia and lobular carcinoma in situ diagnosed on core needle biopsy? A report of 38 cases and review of the literature. Arch Pathol Lab Med 2008;132:979-983.

14 Crisi GM, Mandavilli S, Cronin E, et al. Invasive mammary carcinoma after immediate and short-term follow-up for lobular neoplasia on core biopsy. Am J Surg Pathol 2003;27:325-333.

15 Esserman LE, Lamea L, Tanev S, et al. Should the extent of lobular neoplasia on core biopsy influence the decision for excision? Breast J 2007;13:55-61.

16 Foster MC, Helvie MA, Gregory NE, et al. Lobular carcinoma in situ or atypical lobular hyperplasia at core-needle biopsy: is excision biopsy necessary? Radiology 2004;231:813-819.

17 Hwang H, Barke LD, Mendelson EB, et al. Atypical lobular hyperplasia and classic lobular carcinoma in situ in core biopsy specimens: routine excision is not necessary. Mod Pathol 2008;21:1208-1216.

18 Karabakhtsian RG, Johnson R, Sumkin J, et al. The clinical significance of lobular neoplasia on breast core biopsy. Am J Surg Pathol 2007;31:717-723.

19 Lewis JL, Lee DY, Tratter PI. The significance of lobular carcinoma in situ and atypical lobular hyperplasia of the breast. Ann Surg Oncol 2012;19:4124-4128.

20 Liberman L, Sama M, Susnik B, et al. Lobular carcinoma in situ at percutaneous breast biopsy: surgical biopsy findings. AJR Am J Roentgenol 1999;173:291-299.

21 Mahoney MC, Robinson-Smith TM, Shaughnessy EA. Lobular neoplasia at 11-gauge vacuum-assisted stereotactic biopsy: correlation with surgical excision biopsy and mammographic follow-up. AJR Am J Roentgenol 2006;187:949-954.

22 Margenthaler JA, Duke D, Monsees BS, et al. Correlation between core biopsy and excision biopsy in breast high-risk lesions. Am J Surg 2006;192:534-537.

23 Menon S, Porter GJ, Evans AJ, et al. The significance of lobular neoplasia on needle core biopsy of the breast. Virchows Arch 2008;452:473-479.

24 Middleton LP, Grant S, Stephens T, et al. Lobular carcinoma in situ diagnosed by core needle biopsy: when should it be excised? Mod Pathol 2003;16: 120-129.

25 Nagi CS, O’Donnell JE, Tismenetsky M, et al. Lobular neoplasia on core needle biopsy does not require excision. Cancer 2008;112:2152-2158.

26 O’Neil M, Madan R, Tawfik OW, et al. Lobular carcinoma in situ/atypical lobular hyperplasia on breast needle biopsies: does it warrant surgical excision biopsy? A study of 27 cases. Ann Diagn Pathol 2010;14:251-255.

27 Rendi MH, Dintzis SM, Lehman CD, et al. Lobular in-situ neoplasia on breast core needle biopsy: imaging indication and pathologic extent can identify which patients require excision biopsy. Ann Surg Oncol 2012;19:914-921.

28 Renshaw AA, Derhagopian RP, Martinez P, et al. Lobular neoplasia in breast core needle biopsy specimens is associated with a low risk of ductal carcinoma in situ or invasive carcinoma on subsequent excision. Am J Clin Pathol 2006;126:310-313.

29 Shah-Khan MG, Geiger XJ, Reynolds C, et al. Long term follow up of lobular neoplasia (atypical lobular hyperplasia/ lobular carcinoma in situ) diagnosed on core needle biopsy. Ann Surg Oncol 2012;19: 3131-3138.

30 Shin SJ, Rosen PP. Excisional biopsy should be performed if lobular carcinoma in situ is seen on needle core biopsy. Arch Pathol Lab Med 2002;126:697-701.

31 Subhawong AP, Subhawong TK, Khouri N, et al. Incidental minimal atypical lobular hyperplasia on core needle biopsy: correlation with findings on follow-up excision. Am J Surg Pathol 2010;34: 822-828.

32 Yeh IT, Dimitrov D, Otto P, et al. Pathologic review of atypical hyperplasia identified by image-guided breast needle core biopsy. Correlation with excision specimen. Arch Pathol Lab Med 2003;127:49-54. 
33 Zhao C, Desouki MM, Florea A, et al. Pathologic findings of follow up surgical excision for lobular neoplasia on breast core biopsy performed for calcification. Am J Clin Pathol 2012;138:72-78.

34 D’Orsi CJ, Mendelson EB, Ikeda DM, et al. Breast Imaging Reporting and Data System: ACR BI-RADSBreast Imaging Atlas. American College of Radiology: Reston, VA, 2003.

35 Jacobs TW, Pliss N, Kouria G, et al. Carcinomas in situ of the breast with indeterminate features: role of E-cadherin staining in categorization. Am J Surg Pathol 2001;25:229-236.

36 Bauer VP, Ditkoff BA, Schnabel F, et al. The management of lobular neoplasia identified on percutaneous core breast biopsy. Breast J 2003;9:4-9.

37 Urban JA. Bilaterality of cancer of the breast: biopsy of the opposite breast. Cancer 1967;20:1867-1870.

38 Rosen PP, Senie R, Schottenfeld D, et al. Noninvasive breast carcinoma: frequency of unsuspected invasion and implications for treatment. Ann Surg 1979;189:377-382.

39 Simpson PT, Gale T, Fulford LG, et al. The diagnosis and management of preinvasive breast disease: pathology of atypical lobular hyperplasia and lobular carcinoma in situ. Breast Cancer Res 2003;5: 258-262.

40 Lakhani SR, Audretsch W, Cleton-Jensen AM, et al. The management of lobular carcinoma in situ (LCIS). Is LCIS the same as ductal carcinoma in situ (DCIS)? Eur J Cancer 2006;42:2205-2211.

41 Li CI, Anderson BO, Daling JR, et al. Changing incidence of lobular carcinoma in situ of the breast. Breast Cancer Res Treat 2002;75:259-268.

42 Zhang X, Hanamura N, Yamasita M, et al. A case of lobular carcinoma in situ presenting as a solid mass Br J Radiol 2011;84:e48-e50.

43 Fadare O, Dadmanesh F, Alvarado-Cabrero I, et al. Lobular intraepithelial neoplasia [lobular carcinoma in situ] with comedo-type necrosis: a clinicopathologic study of 18 cases. Am J Surg Pathol 2006;30: 1445-1453.

44 Chivukula M, Bhargava R, Tseng G, et al. Clinicopathologic implications of 'flat epithelial atypia' in core needle biopsy specimens of the breast. Am J Clin Pathol 2009;131:802-808. 